\title{
The Carbon Emissions Efficiency and Marginal Abatement Cost in Urban of China: Non-Parametric Directional Distance Function Method
}

\author{
Jing Zhao \\ Jinan University, Guangzhou, China \\ Email: zjing0311@163.com
}

How to cite this paper: Zhao, J. (2017) The Carbon Emissions Efficiency and Marginal Abatement Cost in Urban of China: Non-Parametric Directional Distance Function Method. Modern Economy, 8, 386396.

https://doi.org/10.4236/me.2017.83028

Received: January 3, 2017

Accepted: March 4, 2017

Published: March 7, 2017

Copyright $\odot 2017$ by author and Scientific Research Publishing Inc. This work is licensed under the Creative Commons Attribution International License (CC BY 4.0).

http://creativecommons.org/licenses/by/4.0/

\begin{abstract}
This paper estimates the $\mathrm{CO}_{2}$ marginal abatement cost of 286 cities in China based on non-parametric directional distance function method for the period of 2002-2013. We compared the results according to different perspectives, such as the areas, the Gross Domestic Product (GDP) per capita and the environmental and non-environmental cities. The results show that the $\mathrm{CO}_{2}$ marginal abatement cost differs obviously among cities and it's higher in eastern area than in middle and western area which indicates that the abatement potential is bigger in middle and western area.
\end{abstract}

\section{Keywords}

Non-Parametric Directional Distance Function, DEA, Marginal Abatement Cost

\section{Introduction}

As we all know, China's economy has made significant progress since the reform and opening up. But with the rapid economic growth, China's carbon emissions are also growing, and now China has become one of the countries who give the biggest contribution to the carbon dioxide emissions [1]. Therefore, how to coordinate the contradiction between carbon dioxide emissions and economic development has become a major problem of sustainable development in China. China's government has proposed that the carbon dioxide emissions of per unit of GDP should reduce by $40 \%-50 \%$ by 2020 compared to emissions in 2005 . However, there are many differences in the economic development and resource endowment between regions and cities due to the large size of China, so the es- 
timation of urban marginal abatement costs can help the government to formulate more effective carbon trading mechanism which will promote the implementation of carbon reduction policies more effectively.

Many literatures about the shadow of the price have been made by scholar home and abroad and the direction distance function has become the main method to estimating shadow prices. The directional distance function was proposed by Chung et al. whose basic idea is to include both the good output and the bad output into the model [2]. That's to say the method not only taking the increase in output into account but also the reduction of bad output, and only when good output cannot continue to expand, mean while bad output cannot continue to shrink, the observation is at the frontier efficiency.

According to the existing literatures, there are two methods to estimate the directional distance function: Parametric method and nonparametric method. The parameterization method needs to select the appropriate model to estimate the directional distance function according to the purpose of the study. Therefore, different models will get different estimating results. Färe et al. used the parametric method to estimate the shadow price of pollutants for the first time on the basis of the Shephard output distance function [3]. Marklund et al. calculated the marginal carbon abatement costs of EU member states based on the parameterized output distance function [4]. Park and Lim estimated the cost of carbon abatement for thermal power plants in Korea based on the logarithmic distance function [5]. Chen $S . Y$ estimates the $\mathrm{CO}_{2}$ shadow prices of different industries in China by using parametric and nonparametric methods [6]. Wei $C$ analyzed the cost and influence factors of carbon abatement in 104 cities of China based on the model [7]. And in his another literature, he estimate marginal $\mathrm{CO}_{2}$ abatement costs at the provincial level in China, and fitted the marginal emission reduction cost curves based on the results [8].

Unlike parametric methods, non parametric methods based on DEA non-parametric approach do not require a specific form of function and specific input and output prices, so it has been widely used in the current literatures. Chamber et al. and Chung et al. proposed the nonparametric directional distance function based on DEA first to study environmental performance and shadow prices including unintended outputs [9]. Boyd et al. and Lee et al. developed the method of calculating shadow prices for unintended outputs in the absence of technology [10] [11]. Kaneko et al. calculated the cost of $\mathrm{SO}_{2}$ emission reduction in China's thermal power industry based on the nonparametric directional distance function [12]. Tu $Z$. G used non-parametric directional distance function to calculate the shadow price of industrial sulfur dioxide in China [13]. Liu M. L et al. estimated the performance of China's provincial carbon emissions and the cost of carbon abatement based on DEA directional distance function [14].

However, most of the literatures are based on the provincial or industry data to estimate the abatement cost and there are few researches focusing on the differences among the cities in China. This paper will use the direction-distance function based on DEA to estimate and analyze the cost of carbon abatement in 
286 prefecture-level cities in China during 2002-2013 and provide a more practical theoretical basis to a perfect carbon trading system.

\section{Methodology}

This paper use the DEA-based directional distance function to estimate the $\mathrm{CO}_{2}$ the carbon dioxide emission performance and shadow prices in 286 cities of China.

\subsection{Output-Oriented Distance Functions}

Consider a joint-production process in which a productive entity employs the input vector $x_{k}=\left(x_{1}, \cdots x_{N}\right) \in R_{+}^{N}$ to produce the desirable output vector $y_{k}=\left(y_{1}, \cdots y_{M}\right) \in R_{+}^{M}$ and the undesirable output vector $b_{k}=\left(b_{1}, \cdots b_{J}\right) \in R_{+}^{J}$. The input vector often includes both energy and non-energy inputs, and the undesirable output vector includes a variety of pollutants or/and green house gases. The joint production process can be modeled by an environmental production technology, which may be represented by an output possibility set

$$
P(x)=\{(y, b): x \text { can produce }(y, b)\}
$$

In the joint-production process, inputs and the desirable output are generally assumed to be strongly or freely disposable, which can be respectively expressed as follows [15]:

$$
\begin{gathered}
x^{\prime} \geq x \text { implies } P\left(x^{\prime}\right) \supseteq P(x) \\
(y, b) \in P(x) \text { and } y^{\prime} \leq y \text { imply }\left(y^{\prime}, b\right) \in P(x)
\end{gathered}
$$

The strong disposability indicates that inputs and good output can be increased or decreased without bearing any costs.

Under the circumstance of environmental regulations, the undesirable outputs cannot be freely disposable, i.e. the productive entity has to undertake a certain amount of cost to reduce the undesirable outputs. Furthermore, the undesirable outputs will be inevitably produced unless the entire production process is terminated. The two important assumptions, which are respectively referred to as weak disposability and null-jointness, make the production technology to be an environmental production technology (or polluting technology). Mathematically, the two assumptions can be respectively given by

$$
\begin{gathered}
(y, b) \in P(x) \text { and } 0 \leq \theta \leq 1 \text { imply }(\theta y, \theta b) \in P(x) \\
\text { if }(y, b) \in P(x) \text { and } b=0 \text {, then } y=0
\end{gathered}
$$

Distance functions are often employed to characterize the environmental production technology described above. Recently, the directional distance function has received increasing attention in energy and environmental performance measurement mainly owing to its flexibility. Following Chung et al. [2] and Färe et al. [16], we formulate the directional output distance function as follows:

$$
D\left(x, y, b, g_{y},-g_{b}\right)=\max \left\{\beta:\left(y+\beta g_{y}, b-\beta g_{b}\right) \in P(x)\right\}
$$

where $\left(g_{y},-g_{b}\right)$ is the directional vector that indicates the direction by which the output combination are scaled, and $\beta$ is the value of the directional distance 
function that measures the largest amount by which $b$ and $y$ can be respectively deflated and inflated given $x$. The smaller of the value of $\beta$, the more efficiency the unit is. If $\beta=0$, then the unit is on the frontier of production and is perfectly efficiency. If $\beta>0$, it means that the good output should be expanded and the bad output should be cut. Following Minglei Liu, we use the value of $\beta$ to estimate the $\mathrm{CO}_{2}$ emission efficiency of cities [14].

Shephard or directional distance function can also be evaluated by data envelopment analysis (DEA). DEA is a popular nonparametric technique for performance evaluation. In energy and environmental studies, DEA has been widely used to benchmark energy and $\mathrm{CO}_{2}$ emission performance. Following Lee and Kaneko, $\beta$, the value of directional distance function can be estimate by the following linear program under the condition of under constant returns to scale [11] [12]:

$$
D_{k}\left(x_{k}, y_{k}, b_{k}, g_{y},-g_{b}\right)=\operatorname{Max} \beta_{k}
$$

s.t.

$$
\begin{gathered}
\sum_{j=1}^{n} \lambda_{j} x_{j} \leq x_{k} \\
\sum_{j=1}^{n} \lambda_{j} y_{j} \geq y_{k}+\beta_{k} g_{y} \\
\sum_{j=1}^{n} \lambda_{j} b_{j}=b_{k}-\beta_{k} g_{b} \\
\lambda \geq 0, j=1,2, \cdots n
\end{gathered}
$$

where $\lambda$ refers to intensity column vector.

\subsection{The Marginal Abatement Costs}

The shadow price of the $j$-th bad output can be specified as Färe et al. [3]:

$$
q_{j}=-p_{m} \cdot\left(\frac{\partial D_{0}(x, y, b ; g) / \partial b_{j}}{\partial D_{0}(x, y, b ; g) / \partial y_{m}}\right)
$$

In a perfect competitive market, the observed market price of them-th good output equals its absolute shadow price $p_{m}$. Consequently, we can represent the shadow price for the $j$-th bad output by the product of our normalizing price of $m$-th good output and the marginal transformation rate between $j$-th bad output and $m$-th good output. The shadow price specification in Eq. (8) captures the loss value in terms of $y_{m}$ when cutting $b_{j}$ marginally on the boundary of $\mathrm{P}(\mathrm{x})$. It reflects the trade-off relationship between bad output and tradable good output and thus can be treated as the marginal abatement cost [4] [8].

\section{Variables and Data}

The data covers 286 cities for the period of 2002-2013. The production of GDP (Y) requires capital stock $(\mathrm{K})$, labor force $(\mathrm{L})$, and energy consumption $(\mathrm{E})$ as inputs and, as a byproduct, yields one undesirable output, $\mathrm{CO}_{2}$ emission (B).

1) The labor input is calculated as the value of employment at the end of the current year; both values are obtained from the China City Statistical Yearbook. 
2) The data on energy consumption are collected from the China Energy Statistical Yearbook, including electricity consumption, gas and liquefied petroleum gas consumption, transportation consumption and heat consumption.

3) The capital stock is unavailable in any statistical yearbook, and therefore, we have to estimate this using the following perpetual inventory method [17]:

$$
K_{i, t}=I_{i, t}+\left(1-\delta_{i}\right) K_{i, t-1}
$$

where $I_{i, t}, \delta_{i}$ and $K_{i, t}$ represent gross investment, depreciation rate, and capital stock for province $i$ at time $t$, respectively. All serial data are converted to 2002 prices.

4) The data on $\mathrm{CO}_{2}$ emission at the city level are not available. Based on the consumption in four sectors, the total $\mathrm{CO}_{2}$ emission can be calculated. The gas and liquefied petroleum gas consumption emission and the heat emission can be calculated directly based on the criteria published by the International Panel on Climate Change (IPCC) (2007). Following Glaeser and Kahn, there is only one emission factor for each regional grid and China Power Grid is divided into North China, Northeast China, East China, Central China, Northwest and South six regional power grid and the regional grid baseline emission factor can be get from the China Energy Statistical Yearbook [18]. So we estimate the electricity emission based on the baseline and emission. Following Hongqi Li, we can estimate the transportation emission based on the certain proportional relationship between energy consumption intensity and carbon emission intensity of various transportation modes [19]; both values are obtained from the China City Statistical Yearbook and the China Statistical Yearbook.

Table 1 lists the descriptive statistics for the variables.

Based on GDP and calculated $\mathrm{CO}_{2}$ emissions, we estimate the intensity of $\mathrm{CO}_{2}$ emissions in each city. The Figure 1 shows the carbon intensity during 20022013 in eastern, central and western respectively. The result reflects that the intensity of carbon emissions in the eastern region is the lowest, and always lower than the national average level, while the carbon emissions intensity in central and western regions over 2002-2013 is always higher than the national average. Especially the western region, the highest carbon intensity in this area reaches 1 . 63 tons/million, showing that the pressure of reducing emissions is still large. However, the energy intensity of carbon emission in China and the three regions is basically declining in the period of 2002-2013 which shows that a series of emission reduction policies implemented by the government have achieved a certain positive effect.

\section{Results}

Based on the DEA model, we obtain the corresponding distance function values and the shadow price of $\mathrm{CO}_{2}$ for each city and make analyses as follows.

\subsection{Carbon Emission Performances}

As mentioned above, the distance function values represent the potential of the observed units to be improved compared to the most efficient point located on 
the frontier of production and the smaller the value, the better the emission performance is. Therefore, this paper analyzes the performance of China's cities' $\mathrm{CO}_{2}$ emissions based on distance function values and the results are shown in Figure 2.

From the comparison of the three regions, the value of the distance function has a great relationship with the degree of economic development in this area. The average distance function value of the economically developed eastern region in 2002-2013 is always the smallest and there are many cities on the frontier. For example, there are 15 cities whose distance function values are zero in

Table 1. Descriptive statistics of the variables.

\begin{tabular}{cccccc}
\hline \multirow{2}{*}{$\begin{array}{c}\text { Input and } \\
\text { output }\end{array}$} & Labor force & $\begin{array}{c}\text { Energy } \\
\text { consumption }\end{array}$ & Capital stock & GDP & CO $_{2}$ emission \\
\cline { 2 - 5 } & $(10,000$ persons $)$ & $(10,000$ Ton $)$ & $(100$ million $)$ & $(100$ million $)$ & $(10,000$ Ton $)$ \\
\hline Mean & 76.64 & 223.25 & 2108.34 & 860.53 & 976.40 \\
Std.dev. & 101.00 & 396.78 & 3663.99 & 1310.34 & 1561.85 \\
Max & 1382.58 & 5028.05 & $48,779.50$ & $17,174.13$ & $17,681.66$ \\
Min & 6.00 & 7.00 & 12.23 & 24.03 & 18.00 \\
\hline
\end{tabular}

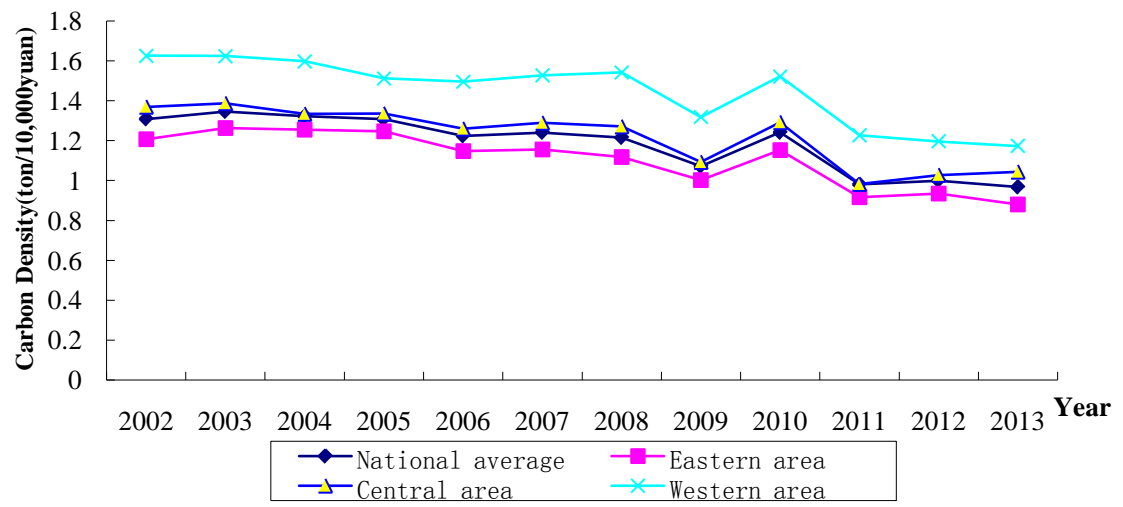

Figure 1. The carbon densities in three areas of China during 2002-2013.

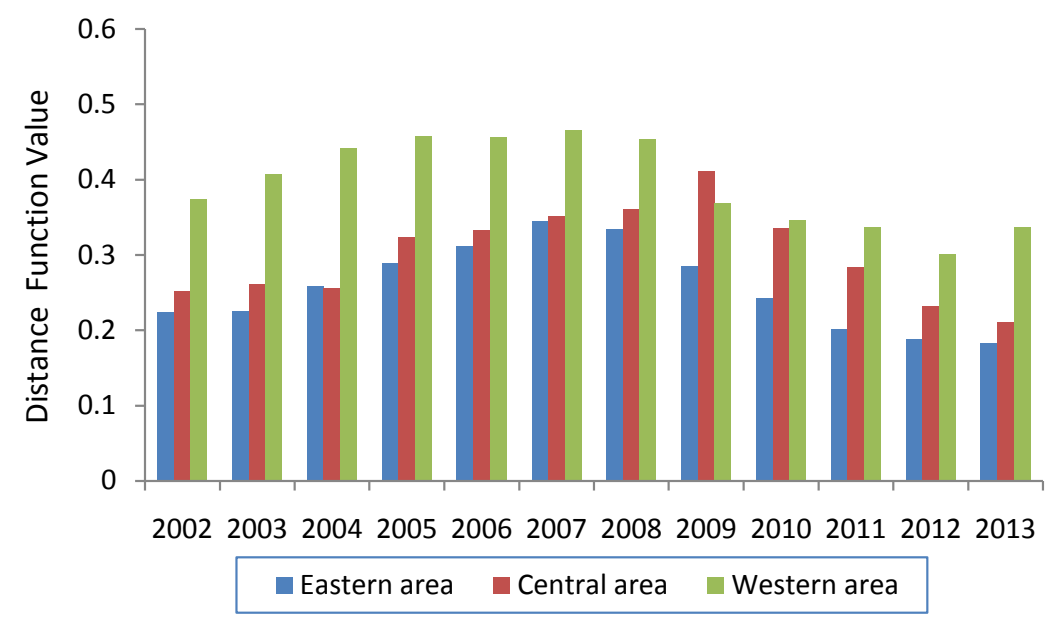

Figure 2. Distance function value of three areas in China during 2002-2013. 
2013 totally and 13 cities belong to the eastern region. In addition, throughout the study period, Suzhou and Ningde are always located on the frontier, and the distance function has always been zero. Followed by the central region, Xuchang has the highest carbon emission efficiency in this area and its distance function value the other years are all zero in addition to year of 2003 and 2013. The value of the distance function is the highest in the western region, where is relatively backward in economic development and its average distance function value during 2002-2013 is more than 0.4. This indicates that the eastern region is the most efficient in carbon emissions compared to the central and western regions. That's to say, the central and western regions, especially the western region, have significant potential for reducing emissions.

However, the distance function values of the three regions all shows a decreasing trade after 2006. This phenomenon indicates that in one hand China's carbon emission reduction policy has achieved positive results and carbon emissions efficiency is improving; in another hand it reflects that China's carbon emission abatement space is gradually declining and the task of reducing emissions may become more and more difficult.

\section{2. $\mathrm{CO}_{2}$ Marginal Abatement Costs}

Table 2 describes the $\mathrm{CO}_{2}$ marginal abatement costs in the three regions. According to the mean of the marginal cost of emission reduction in the three regions, the eastern and western regions are all higher than the national average, while the central region is relatively low and is below the national average. The estimating of nuclear kernel density of each city's marginal emission abatement cost can reflects its general distribution and four years' emission reduction data are choose to estimate the nuclear kernel density. The results are shown in Figure 3. From Figure 3, we find that the kernel density curve gradually shifted to the right with time. The distribution of the $\mathrm{CO}_{2}$ marginal abatement costs was highly concentrated at 2500 yuan/ton level in 2002, while it increases to 3600 yuan/ton in 2013. This indicates that the mean and variance of the cities' marginal abatement costs have been on the increase since 2002.

Figure 4 shows the estimating results of the $\mathrm{CO}_{2}$ marginal abatement costs in three regions and the whole of the country during 2002-2013. We can find that the lowest marginal cost of emission abatement in the country is about $4000 \mathrm{yu}$ an per ton. From the regional comparison, we find that the marginal abatement costs in the eastern region are generally more than 4000 yuan/ton and the highest cost is about 5437 yuan/ton in 2002. While the central region's marginal abatement cost is always lower than the national average except for 2013. The western region's abatement costs change irregularly, but are generally higher than the national level. The results indicate that the eastern region has a relatively higher level of economic development, advanced technology, and energy efficiency, which has resulted in the lower carbon intensity in the region. That's to say, the cities in eastern region will have to pay a greater economic cost if they continue to reduce carbon emissions. While the central region's higher carbon 
intensity shows that there is a large potential for the cities to reduce emission and the economic costs of emission reduction is relatively lower.

Table 2. Descriptive statistics of the $\mathrm{CO}_{2}$ marginal abatement costs.

\begin{tabular}{cccccc}
\hline Area & Sample size & Mean & Std.dev. & Max & Min \\
\hline Eastern & 1212 & 4719.44 & 3992.31 & $34,949.07$ & 173.83 \\
Central & 1212 & 4315.37 & 5340.95 & $132,443.86$ & 94.50 \\
Western & 1008 & 4631.83 & 4605.76 & $29,992.69$ & 31.91 \\
National & 3432 & 4552.36 & 4685.56 & $132,443.86$ & 31.91 \\
\hline
\end{tabular}

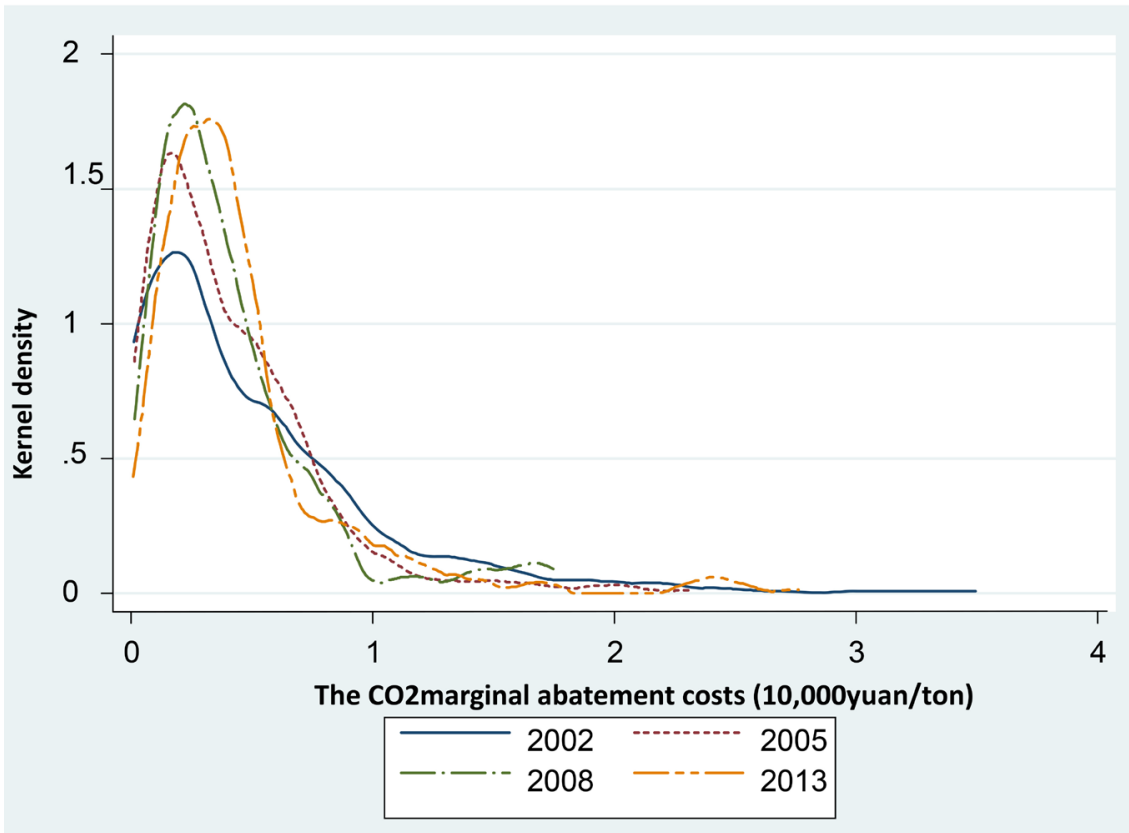

Figure 3. Kernel density evolution of the $\mathrm{CO}_{2}$ marginal abatement costs.

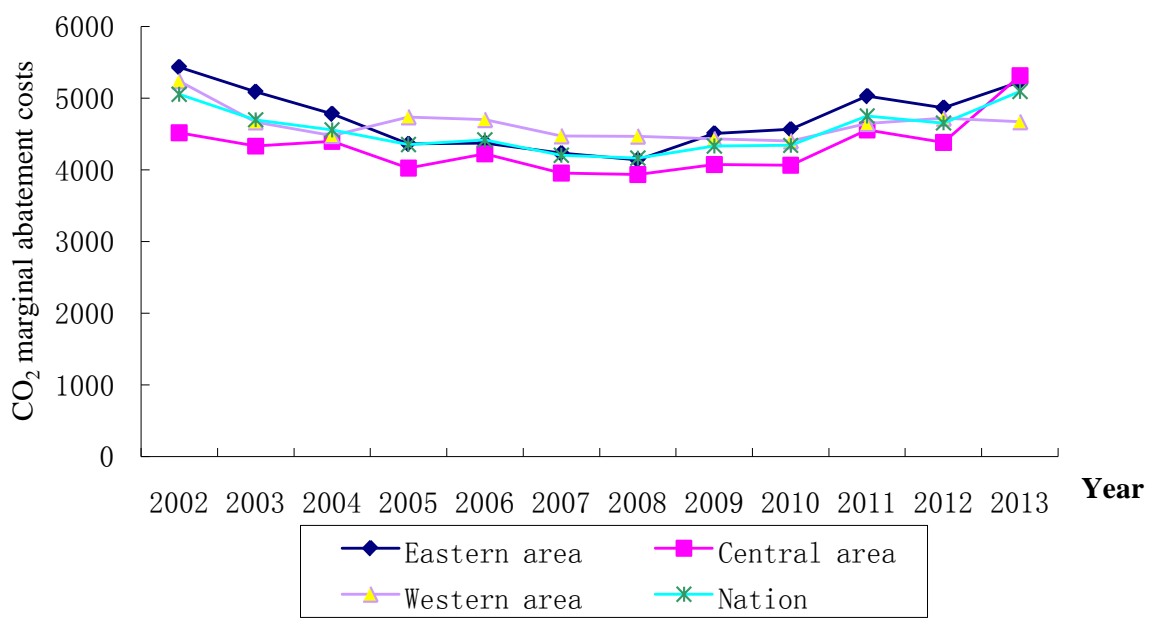

Figure 4. The $\mathrm{CO}_{2}$ marginal abatement costs of three areas in China. 
For the change trend, the eastern and central regions and the country's carbon marginal abatement cost tend to be the same and can be divided into three phases. The first stage is from 2002-2005. The abatement costs in the above areas are all showing a downward trend in this period and it's much more obvious in the eastern where the average abatement cost of decreased from about $5437 \mathrm{yu}$ an/ton in 2002 to about 4363 yuan/ton in 2005, with a25 percent decline rate. The second stage is from 2005 to 2008. The marginal abatement costs of the above regions are basically stable during this stage and the costs of eastern are very close to those of nation. The last stage is from 2008 to 2013. Abatement costs in this period are beginning to show a trend of growth. Although there is a short decline to 4385 yuan/ton in 2012, they have shown a more substantial growthto 5314 yuan/ton in 2013, increasing about 21\%. This growing trend of abatement costs indicates that as the implementation of China's "11th Five-Year" plan and energy conservation and emission reduction policies, reducing emission becomes more and more difficult in the whole nation. However, the western region's abatement cost shows a different trend and can still be divided into three stages. The first phase is from 2002-2004. In this period, the marginal abatement costs reduce from 5340.61 yuan/ton to 4478 yuan/ton. The second phase is 2004-2005. The cost shows a slight increase in 2005 and reach to 4738 yuan/ton. The last stage is from 2005-2013. The marginal abatement cost at this stage basically shows a stable development trend. This steady trend shows that the impact of the "energy saving and emission reduction" program in the western region is relatively small compared to the eastern and central regions. Besides, the carbon intensity and distance function values in western region are relatively higher, indicating that the western region exists greater potential and space to implement mitigation measures.

\section{Conclusions}

The World Bank has made estimates that the greenhouse gases produced by energy consumption in cities of China take around $70 \%$ of the total greenhouse gas emissions in the whole China. Therefore, it's necessary for China to control greenhouse gas emissions and implement energy-saving and emission reduction policies in cities. In this paper, we use the parameterized directional distance function to estimate the $\mathrm{CO}_{2}$ emission efficiency and marginal abatement of 286 prefecture-level cities in China covering years from 2002 to 2013 and draws conclusions as follows.

1) There are obvious differences in $\mathrm{CO}_{2}$ emission efficiency among the three regions. The cities in eastern region have the smallest distance function values and many cities are on the frontier. That's to say, the eastern area is the most efficiency in energy consumption. The distance function of the western region is the largest and the average values are more than 1.2 during the study period; moreover, there is almost no city in this area on the frontier. The results show that the carbon emissions efficiency is closely linked with a city's economy and technology development. Compared to the cities in eastern area, those in west- 
ern region are less development both in economy and technology and there is still much space to improve. That means that the emission reduction potential in western region is the largest, while the eastern region is the smallest. But the abatement cost of the three regions shows an increasing trend year by year overall, indicating that a series of carbon emission reduction measures implemented in recent years have played a role and at the same time it means that the difficulty of continuing to reduce emissions is growing.

2) The $\mathrm{CO}_{2}$ marginal abatement costs are also very different in the three regions. The marginal costs of the cities in eastern region are always higher than the national average and are basically higher than 4000 yuan/ton which means that if the government continues to reduce emissions in these regions, they will pay a higher economic cost. The central and western regions have relatively lower emission abatement costs. In particular, the costs in central region are always lower than the national average except for the year of 2013 and the average abatement cost of Yangquan in Shanxi province is only 340 yuan/ton. Although there is a rising trend in the region due to the increasingly stringent environmental regulation in the central region, the potential of emission reduction in the cities of this area is still larger compared to those of eastern area. Moreover, the marginal abatement costs of western cities are basically stable after 2005and the differences between the western and central region are decreasing year by year. Besides, the western region still has great potential for reducing emissions.

The results obtained in this paper may provide some references for the implementation of carbon policy in China. The statistics show that in the first two years of the 12th five-year plan (2011-2012), China's energy intensity fell by $2.02 \%$ and $3.62 \%$ respectively which are all smaller than the defined target about $3.7 \%$. Based on the above analysis, a one-size-fits-all carbon reduction policy is extremely unfavorable to the economically developed cities in eastern region and the government should take into account the specific conditions of each city in formulating specific emission reduction policies. For example, there are obvious differences in emission abetment costs among the three regions so that the eastern region where has relatively higher abatement cost should continue to maintain the existing economic development mode to promote economy development and buy emission permits to achieve emission reduction targets at the same time using the carbon trading mechanism. While the central and western regions should continue to improve the technical level to improve energy efficiency and to achieve the goal of energy-saving and emission reduction.

\section{References}

[1] BP. Statistical Review of World Energy, 2011.

[2] Chung, Y.H., Färe, R. and Grosskopf, S. (1997) Productivity and Undesirable Outputs: A Directional Distance Function Approach. Journal of Environmental Management, 51, 229-240. https://doi.org/10.1006/jema.1997.0146

[3] Färe, R., Grosskopf, S., Lovell, C.A.K., et al. (1993) Derivation of Shadow Prices for Undesirable Outputs: A Distance Function Approach. The Review of Economics and Statistics, 374-380. https://doi.org/10.2307/2109448 
[4] Marklund, P.O. and Samakovlis, E. (2007) What Is Driving the EU Burden-Sharing Agreement: Efficiency or Equity? Journal of Environmental Management, 85, 317329. https://doi.org/10.1016/j.jenvman.2006.09.017

[5] Park, H. and Lim, J. (2009) Valuation of Marginal $\mathrm{CO}_{2}$ Abatement Options for Electric Power Plants in Korea. Energy Policy, 37, 1834-1841.

https://doi.org/10.1016/j.enpol.2009.01.007

[6] Chen, S.Y. (2010) Shadow Price of Industrial Carbon Dioxide: Parametric and Nonparametric Methods. World Economy, No. 8, 93-111.

[7] Wei, C. (2014) CO2 MarginalAbatement Costs of Urban in China and Its Influencing Factors. World Economy, No. 7, 115-141.

[8] Wei, C., Ni, J. and Du, L. (2012) Regional Allocation of Carbon Dioxide Abatement in China. China Economic Review, 23, 552-565. https://doi.org/10.1016/j.chieco.2011.06.002

[9] Chambers, R.G., Chung, Y. and Färe, R. (1996) Benefit and Distance Functions. Journal of Economic Theory, 70, 407-419. https://doi.org/10.1006/jeth.1996.0096

[10] Boyd, G., Molburg, J. and Prince, R. (1996) Alternative Methods of Marginal Abatement Cost Estimation: Non-Parametric Distance Functions. Argonne National Lab., IL (United States). Decision and Information Sciences Div.

[11] Lee, J.D., Park, J.B. and Kim, T.Y. (2002) Estimation of the Shadow Prices of Pollutants with Production/Environment Inefficiency Taken into Account: A Nonparametric Directional Distance Function Approach. Journal of Environmental Management, 64, 365-375. https://doi.org/10.1006/jema.2001.0480

[12] Kaneko, S., Fujii, H., Sawazu, N., et al. (2010) Financial Allocation Strategy for the Regional Pollution Abatement Cost of Reducing Sulfur Dioxide Emissions in the Thermal Power Sector in China. Energy Policy, 38, 2131-2141. https://doi.org/10.1016/j.enpol.2009.06.005

[13] Tu, Z.G. (2009) The Shadow Price of Sulfur Dioxide Emission in Industry: A New Analytical Framework. Economics Quarterly, 9, 259-282.

[14] Liu, M.L., Zhu, L. and Fan, Y. (2011) Estimation of China's Provincial Performance of Carbon Emissions and Estimation of Marginal Emission Reductions: Based on Nonparametric Distance Function Method. Soft Science of China, No. 3, 106-114.

[15] Färe, R. and Primont, D. (2012) Multi-Output Production and Duality: Theory and Applications. Springer Science \& Business Media, Berlin.

[16] Färe, R., Grosskopf, S. and Pasurka, C.A. (2007) Environmental Production Functions and Environmental Directional Distance Functions. Energy, 32, 1055-1066. https://doi.org/10.1016/j.energy.2006.09.005

[17] Zhang, J., Wu, G.Y. and Zhang, J.P. (2007) Estimating China's Provincial Capital Stock. Working Paper Series, China Center for Economic Studies, Fudan University, Shanghai.

[18] Glaeser, E.L. and Kahn, M.E. (2010) The Greenness of Cities: Carbon Dioxide Emissions and Urban Development. Journal of Urban Economics, 67, 404-418. https://doi.org/10.1016/j.jue.2009.11.006

[19] Li, H., Lu, Y., Zhang, J., et al. (2013) Trends in Road Freight Transportation Carbon Dioxide Emissions and Policies in China. Energy Policy, 57, 99-106. https://doi.org/10.1016/j.enpol.2012.12.070 
Submit or recommend next manuscript to SCIRP and we will provide best service for you:

Accepting pre-submission inquiries through Email, Facebook, LinkedIn, Twitter, etc. A wide selection of journals (inclusive of 9 subjects, more than 200 journals)

Providing 24-hour high-quality service

User-friendly online submission system

Fair and swift peer-review system

Efficient typesetting and proofreading procedure

Display of the result of downloads and visits, as well as the number of cited articles Maximum dissemination of your research work

Submit your manuscript at: http://papersubmission.scirp.org/

Or contact me@scirp.org 